(RESEARCH ARTICLE)

\title{
Exercise reduces plasma lipid levels by downregulating tumor necrosis factor- $\alpha$ production by peripheral blood mononuclear cells
}

\author{
Smith John ${ }^{1,}{ }^{*}$, Dykes Rhesa ${ }^{2}$ and Chi David S ${ }^{3}$ \\ ${ }^{1}$ Department of Academic Affairs, James H. Quillen College of Medicine, East Tennessee State University, PO Box 70300, \\ Johnson City, Tennessee 37614, USA. \\ ${ }^{2}$ Department Biomedical Sciences, James H. Quillen College of Medicine, East Tennessee State University, PO Box 70577, \\ Johnson City, Tennessee 37614, USA. \\ ${ }^{3}$ Department of Internal Medicine, James H. Quillen College of Medicine, PO Box 70300, East Tennessee State University, \\ Johnson City, Tennessee 37614, USA
}

Publication history: Received on 07 June 2020; revised on 16 June 2020; accepted on 18 June 2020

Article DOI: https://doi.org/10.30574/wjarr.2020.6.3.0192

\begin{abstract}
Tumor necrosis factor alpha (TNF- $\alpha$ ), a proinflammatory/proatherogenic cytokine, has been implicated as the cause hyperlipidemia in patients with chronic inflammatory joint disease including rheumatoid arthritis, psoriatic arthritis and ankylosing spondylitis. In this study, we have measured the effect of long-term moderate intensity exercise training on blood lipid levels and on the ex vivo production of TNF- $\alpha$ by mitogen-stimulated peripheral blood mononuclear cells. Study participants underwent six-months of tri-weekly supervised training sessions, each consisted of a combination of aerobic (52\%), resistance (40\%), and flexibility (8\%) exercises. Forty-three subjects, 25 women average age 49.7 years and 18 men average age 48.1 years, successfully completed the study. Both men and women exercised an average of 2.5 hours per week. Exercise training resulted in a 10\% decrease in total cholesterol levels $(\mathrm{P}=0.0136)$, an 18\% decrease in low density lipoprotein cholesterol levels ( $\mathrm{P}=0.0043)$, a $20.1 \%$ decrease in total cholesterol/high density lipoprotein cholesterol ratios $(\mathrm{P}=0.0030)$, and a $51.5 \%$ decrease in the production of TNF- $\alpha(\mathrm{P}<0.0001)$. On multiple regression analysis reductions in TNF- $\alpha$ correlated linearly with reductions in total cholesterol $(\mathrm{R}=0.4185, \mathrm{~F}=8.4931$, $\mathrm{P}=0.0058)$ and low density lipoprotein cholesterol $(\mathrm{R}=0.3562, \mathrm{~F}=5.8138, \mathrm{P}=0.0206)$. We conclude that exercise-related reductions in blood lipids may occur as the result of reductions in immune cell production of TNF- $\alpha$, a cytokine with known potential to influence hepatic, adipocyte, and monocyte/macrophage regulation of lipid metabolism.
\end{abstract}

ClinicalTrials.gov identifier: NCT04195932

Keywords: Exercise; Cholesterol; Tumor necrosis factor- $\alpha$; Hyperlipidemia; Atherogenesis; Rheumatoid arthritis.

\section{Introduction}

There has been a world-wide reduction in the levels of physical activity in both adults and children, with insufficient physical activity accounting for an estimated 69.3 million disability-adjusted life years and 3.2 million deaths in 2010 [1]. Cardiovascular diseases (CVD) account for more than one-half of NCD deaths in nearly every region of the world [2] with hyperlipidemia, hypertension, tobacco smoking, sedentary lifestyles, obesity, diabetes mellitus and the metabolic syndrome being its most consistent risk factors globally [3-5].

One of the health benefits of physical activity is its potential to increase blood levels of high density lipoprotein cholesterol and lower blood levels of total cholesterol and low density lipoprotein cholesterol [6-9]. The mechanism(s) whereby these favorable changes in blood lipid levels occur in response to physical exercise, however, is incompletely understood.

\footnotetext{
${ }^{*}$ Corresponding author: Smith John
} 
Tumor necrosis factor-alpha (TNF- $\alpha$ ) is a proinflammatory cytokine that has been implicated as the cause of hyperlipidemia in persons with chronic inflammatory joint diseases, including those with rheumatoid arthritis, ankylosing spondylitis, and psoriatic arthritis [10-13]. We now report the effects of long term combined aerobic and resistance exercise training on plasma lipid levels and on the ex vivo production of TNF- $\alpha$ by mitogen-stimulated peripheral blood mononuclear cells.

\section{Material and methods}

This study was approved by the James H. Quillen College of Medicine's Institutional Review Board. All participants signed an informed consent in the presence of one of the investigators.

\subsection{Subjects}

Subjects aged 30 to 60 were recruited from the general population by placing an outline of the study and a request for volunteers in local newspapers. A total of 77 persons responded and were screened for eligibility. Eligibility criteria included a normal EKG, a normal stress test, and absence of chronic inflammatory disease, malignancy, immunodeficiency, or immunosuppressive therapy.

Fifty-two subjects met eligibility criteria and were enrolled in a hospital-based wellness center where they underwent 6 months of supervised exercise training. Each training session consisted of a combination of aerobic (52\%), resistance (40\%), and flexibility (8\%) exercises. Aerobic exercises choices included walking, running, cycling, climbing, rowing, and aerobics. Resistance exercises consisted of weightlifting and flexibility exercises consisted of stretching.

Forty-three subjects ( 25 women, average age $49.7 \pm 7.2$ years, range $30-59$, and 18 men, average age $48.1 \pm 8.0$ years, range 35-59) successfully completed the study (data are given as the mean \pm standard error of the mean [SEM]). Nine subjects (eight men and one woman) were excluded: eight did not meet attendance requirements and one moved to another location.

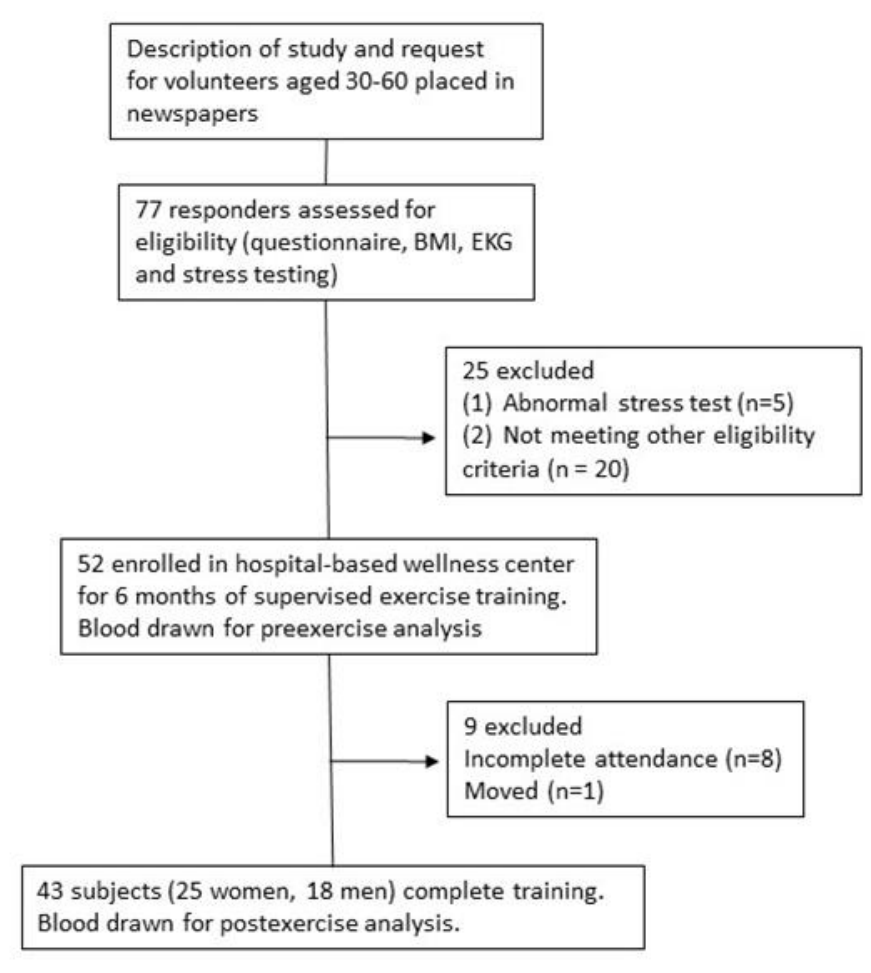

Figure 1 Eligibility criteria: normal EKG, stress test, and exercise tolerance; absence of chronic inflammatory disease, malignancy, immunodeficiency, and immunosuppressive therapy.

Prior to the trial, $40 \%$ of the 43 subjects (36\% of women, $44 \%$ of men) had done unsupervised aerobic exercises (walking and/or running) for an average of $1.65 \pm 0.43$ hours/week for $1.49 \pm 0.76$ years. Women averaged $1.31 \pm 0.46$ 
hours/week for $0.55 \pm 0.24$ years and men averaged $2.11 \pm 0.80$ hours per week for $2.80 \pm 1.78$ years. No correlation was found between their reported times of exercise and pre-trial lipid or TNF- $\alpha$ levels.

Supervisors kept detailed records documenting attendance, the duration and type of each exercise, weights, changes in medications, changes in dietary or smoking habits, and state of health. These data were analyzed for their potential effects on outcome measurements and for group and within-group differences.

Men exercised an average of $2.46 \pm 0.50$ hours per week and women exercised an average of $2.45 \pm 0.38$ hours per week. Men spent $52.6 \%$ of their time doing aerobic exercises, $39.4 \%$ of their time doing resistance exercises, and $8 \%$ of their time doing flexibility exercises. Women spent $56.7 \%$ of their time doing aerobic exercises, $35.5 \%$ of their time doing resistance exercises, and $7.8 \%$ of their time doing flexibility exercises ( $\mathrm{P}>0.05$, men versus women).

Blood was drawn at baseline and after completion of exercise training. Subjects were instructed not to exercise outside of the supervised exercise program and for at least 24 hours prior to blood drawing. All blood samples were drawn in the morning at approximately the same time.

\subsection{Lipoprotein isolation}

Lipoproteins were isolated from $2 \mathrm{~mL}$ of subjects' pre- and post-exercise fasting plasma samples by the method of Kleinveld et. al. [14] using a Beckman g-max system, a Model L5 75 ultracentrifuge, and a Type 80 Ti rotor. Plasma samples were placed in g-Max Quick-Seal tubes, filled with potassium bromide [KBr] $(\mathrm{d}=1.006 \mathrm{~g} / \mathrm{mL})$ to a total volume of $4.2 \mathrm{~mL}$, sealed, and centrifuged for 120 minutes at $68,000 \mathrm{rpm}$ at $14^{\circ} \mathrm{C}$. Very low density lipoproteins [VLDL] were removed and the bottom portion ( $3.7 \mathrm{~mL}$ ) adjusted to a density of $1.063 \mathrm{~g} / \mathrm{mL}$ by adding $0.3 \mathrm{~g}$ of $\mathrm{KBr}$, sealed, and centrifuged for 150 minutes at $68,000 \mathrm{rpm}$ at $14^{\circ} \mathrm{C}$ to float the low density lipoproteins which were harvested by pipetting. The bottom portion of the tube contained the high density lipoproteins. All solutions contained $0.5 \mathrm{mg} / \mathrm{mL}$ EDTA to prevent lipoprotein oxidation. Total cholesterol [TC], VLDL, low density lipoprotein cholesterol [LDL-C], and high density lipoprotein cholesterol [HDL-C] content was measured colorimetrically using a kit from Sigma (Procedure number 352, Sigma Chemical Company, St. Louis, Mo).

\subsection{Cytokine Production}

Peripheral blood mononuclear cell [PBMC] preparations containing 80-85\% lymphocytes and $15-20 \%$ monocytes were isolated from venous blood using Accu-Prep ${ }^{\mathrm{TM}}$ (Accurate Chemical \& Scientific Corp., Westbury, NY), washed three times at $10^{\circ} \mathrm{C}$ with phosphate buffered saline ( $\left.\mathrm{pH} 7.4,0.1 \mathrm{M}\right)$, and suspended at a concentration of $2 \times 10^{6}$ cells/ $\mu \mathrm{L}$ in RPMI1640. Preparations were incubated under $5 \% \mathrm{CO}_{2}$ at $37^{\circ} \mathrm{C}$ for 48 hours with phytohemagglutinin $(5 \mu \mathrm{g} / \mathrm{ml})$, a lectin mitogen that stimulates unprimed $\mathrm{T}$ cells to proliferate by cross-linking their $\mathrm{T}$ cell receptors. Culture supernatants were rendered cell-free by centrifuging at $1,000 \mathrm{x}$ g for 10 minutes at $12^{\circ} \mathrm{C}$. Supernatants were assayed for tumor necrosis factor-alpha [TNF- $\alpha$ ] using solid phase enzyme linked immunoassay kits (Genzyme Corp, Cambridge, Mass).

\subsection{Statistical analysis}

The threshold $\mathrm{p}$ value (alpha) is set at $0.05\left({ }^{*} \mathrm{P} \leq 0.05,{ }^{* *} \mathrm{P} \leq 0.01,{ }^{* * *} \mathrm{P} \leq 0.001,{ }^{* * *} \mathrm{P} \leq 0.0001\right)$. Two-tailed Fisher's exact test for matched pairs was used to analyze the significance of observed versus expected frequency of attributes. Multiple regression analysis was done to determine the correlation between dependent and independent variables. Results are given as the mean \pm SEM. TIBCO Statistica, Academic Version 13.3, 2017, was used as statistical software.

\section{Results}

\subsection{Effect of exercise on weight}

Subject weights fell by $1.7 \%$ ( $80.6 \pm 2.8$ to $79.2 \pm 3.0 \mathrm{~kg}$ ) following exercise training. In women, weights fell by $2.7 \%$ $(72.3 \pm 2.7$ to $69.6 \pm 2.1 \mathrm{~kg})$ and in men weights fell by $0.8 \%(92.1 \pm 4.2$ to $91.4 \pm 4.9 \mathrm{~kg})$. These changes are not statistically significant $(\mathrm{P}>0.05)$.

\subsection{Effect of exercise on plasma lipid levels}

Following exercise training, TC fell 10\% ( $\mathrm{P}=0.0136)$, LDL-C fell 18\% ( $\mathrm{P}=0.0043)$, HDL-C increased 12.3\% ( $>0.05)$, and the HDL/TC ratio fell $20.1 \%(P=0.0030)$ (two-tailed T-test). There was no statistically significant change in VLDL values. 


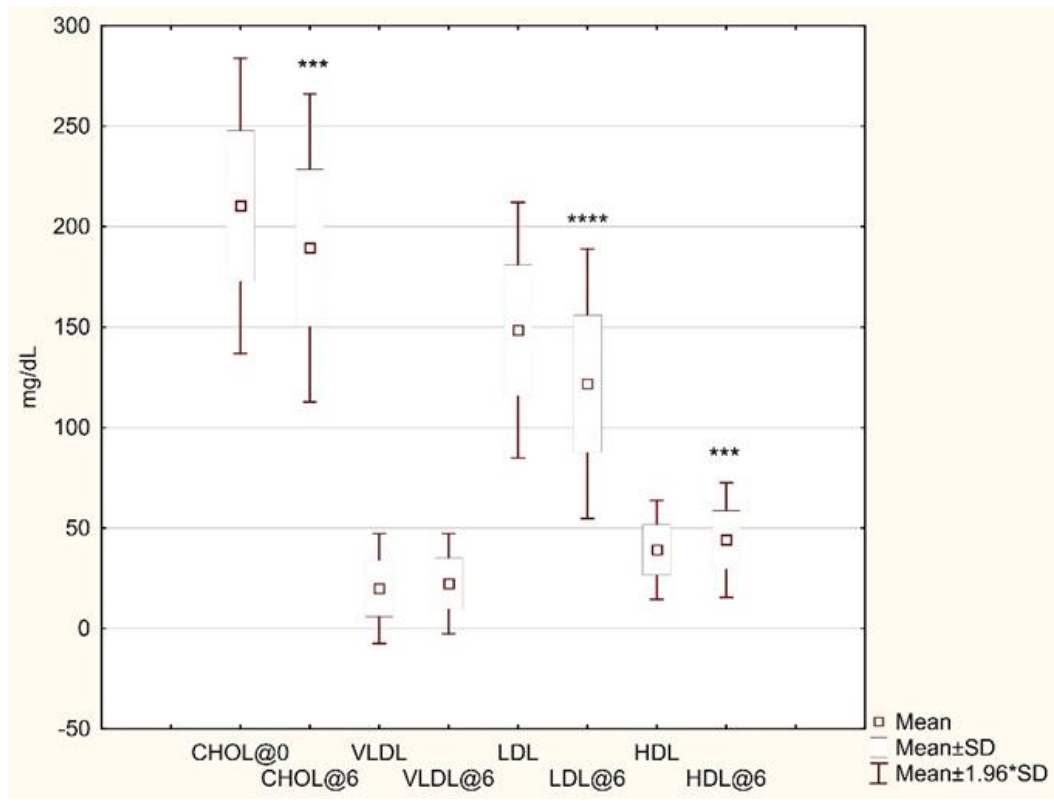

Figure 2 Effect of exercise on plasma lipid levels

Box and whisker graph of pre- and post-exercise plasma lipid levels. Following exercise training, TC fell $10 \%$ ( $\mathrm{P}=0.0136)$, LDL-C fell 18\% ( $\mathrm{P}=0.0043)$, HDL-C increased 12.3\% ( $\mathrm{P}>0.05)$, and the HDL/TC ratio fell 20.1\% ( $\mathrm{P}=0.0030)$ (two-tailed T-test). There was no statistically significant change in VLDL values. In women, exercise training resulted in a $13.2 \%$ decrease in TC levels $(\mathrm{P}=0.0100)$, a $23.3 \%$ decrease in LDL-C levels $(\mathrm{P}=0.0006)$, a $24.1 \%$ decrease in TC/HDL ratios $(\mathrm{P}=0.0123)$, and a $15.2 \%$ increase in HDL-C levels $(\mathrm{P}>0.05)$. In men, exercise training resulted in a $5.2 \%$ decrease in TC levels, a 10.8\% decrease in LDL-C levels, a 15.6\% decrease in TC/HDL ratios and a 5.6\% increase in HDL-C levels. These changes, although favorable, did not reach statistical significance $(\mathrm{P}>0.05)$. This may be attributable to the higher incidence of hypertension and obesity in men as compared to women, although the exact reason is not known. There were no statistically significant changes in VLDL levels in the study group as a whole or in women or men following exercise training.

Table 1 Effect of Exercise on Plasma Lipid Levels

\begin{tabular}{|c|c|c|c|c|}
\hline & Preexercise & Postexercise & \% change & P-value \\
\hline $\mathrm{TC}$ & $210(5.7)$ & $189(6)$ & -10 & 0.0136 \\
\hline q & 213 (7.9) & $184.8(7.2)$ & -13.2 & 0.0100 \\
\hline$\widehat{0}$ & $206.2(8.4)$ & $195.5(10.4)$ & -5.2 & $>0.05$ \\
\hline LDL-C & $148.5(5.0)$ & $121.8(5.3)$ & -18 & 0.0043 \\
\hline q & $149.4(7.2)$ & $114.6(6.2)$ & -23.3 & 0.0006 \\
\hline$\widehat{0}$ & $147.2(7.0)$ & $131.3(8.8)$ & -10.8 & $>0.05$ \\
\hline HDL-C & $39.2(1.9)$ & $44.0(2.3)$ & +12.3 & $>0.05$ \\
\hline q & $42.8(2.6)$ & $49.3(3.3)$ & +15.2 & $>0.05$ \\
\hline$\widehat{\theta}$ & $34.4(2.7)$ & $37.0(1.9)$ & +5.6 & $>0.05$ \\
\hline VLDL & $19.8(2.2)$ & $22.3(2.2)$ & +12.6 & $>0.05$ \\
\hline q & $18.6(2.9)$ & $20.9(3.0)$ & +12.4 & $>0.05$ \\
\hline$\sigma^{\lambda}$ & $21.5(3.3)$ & $24.2(2.4)$ & +12.6 & $>0.05$ \\
\hline TC/HDL Ratio & $5.8(0.3)$ & $4.7(0.2)$ & -20.1 & 0.0030 \\
\hline q & $5.4(0.4)$ & $4.1(0.3)$ & -24.1 & 0.0123 \\
\hline 0 & $6.4(0.4)$ & $5.4(0.3)$ & -15.6 & $>0.05$ \\
\hline
\end{tabular}

Cholesterol values are given as mg/dL. Data are presented as the mean (SEM). TC, total cholesterol; LDL-C, low density lipoprotein cholesterol; HDL-C, high density lipoprotein cholesterol; VLDL, very low-density lipoprotein cholesterol. 


\section{Effect of exercise on TNF- $\alpha$ production}

Following exercise training, TNF- $\alpha$ production fell 51.5\% (P <0.0001). In women TNF- $\alpha$ production fell $55.7 \%$ $(\mathrm{P}<0.0001)$ and in men TNF- $\alpha$ production fell $46.2 \%(\mathrm{P}=0.0106)$.

Table 2 Effect of Exercise on the Production of TNF- $\alpha \dagger$

\begin{tabular}{|c|c|c|c|c|}
\hline & Pre-exercise & Post-exercise & $\%$ change & $\mathbf{P}$ \\
\hline TNF- $\alpha(\mathrm{pg} / \mathrm{ml})$ & 3340 (293) & $1621(180)$ & -51.5 & $\mathrm{P}<0.0001$ \\
\hline q & 3188 (316) & $1411(250)$ & -55.7 & $\mathrm{P}<0.0001$ \\
\hline $0^{\pi}$ & $3552(555)$ & $1912(246)$ & -46.2 & $P=0.0106$ \\
\hline
\end{tabular}

Data are presented as the mean \pm SEM. $†$ Cellular sources of TNF- $\alpha$ include activated Th1 lymphocytes, CD8+ cytotoxic lymphocytes, natural killer cells, and M1-polarized macrophages.

On multiple linear regression analysis with lipid values as the dependent variables and cytokine values as the independent variables, post-exercise reductions in TNF- $\alpha$ correlated with post-exercise reductions in plasma levels of TC and LDL-C.
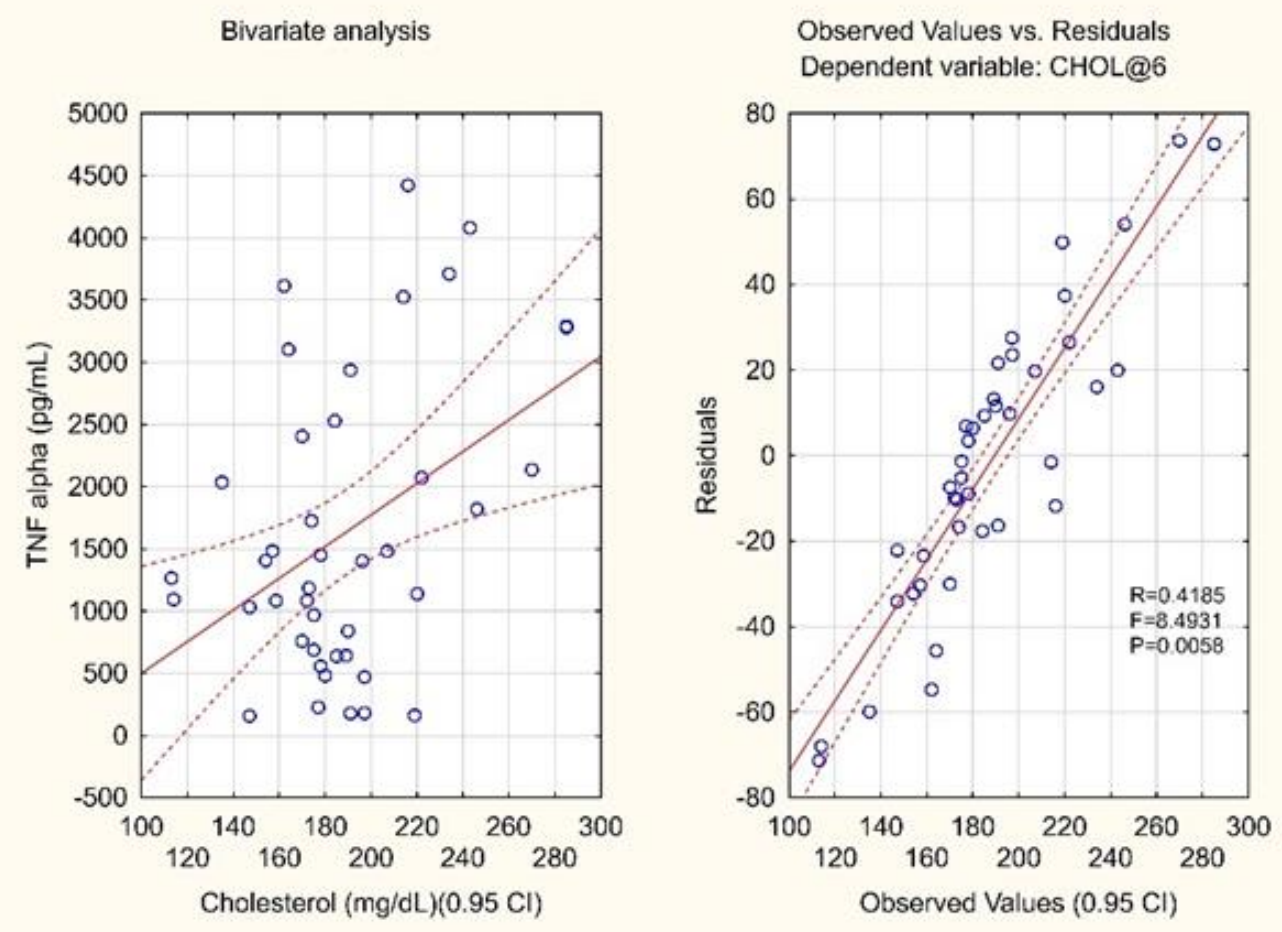

Figure 3 Correlation of TNF- $\gamma$ and total cholesterol

Multiple regression analyses of post-exercise TNF- $\alpha$ (independent variable) and total cholesterol (dependent variable). On bivariate and residual analysis, the correlation between these two variables is statistically significant $(\mathrm{R}=0.4185$, $\mathrm{F}=8.4931, \mathrm{P}=0.0058$ ). 

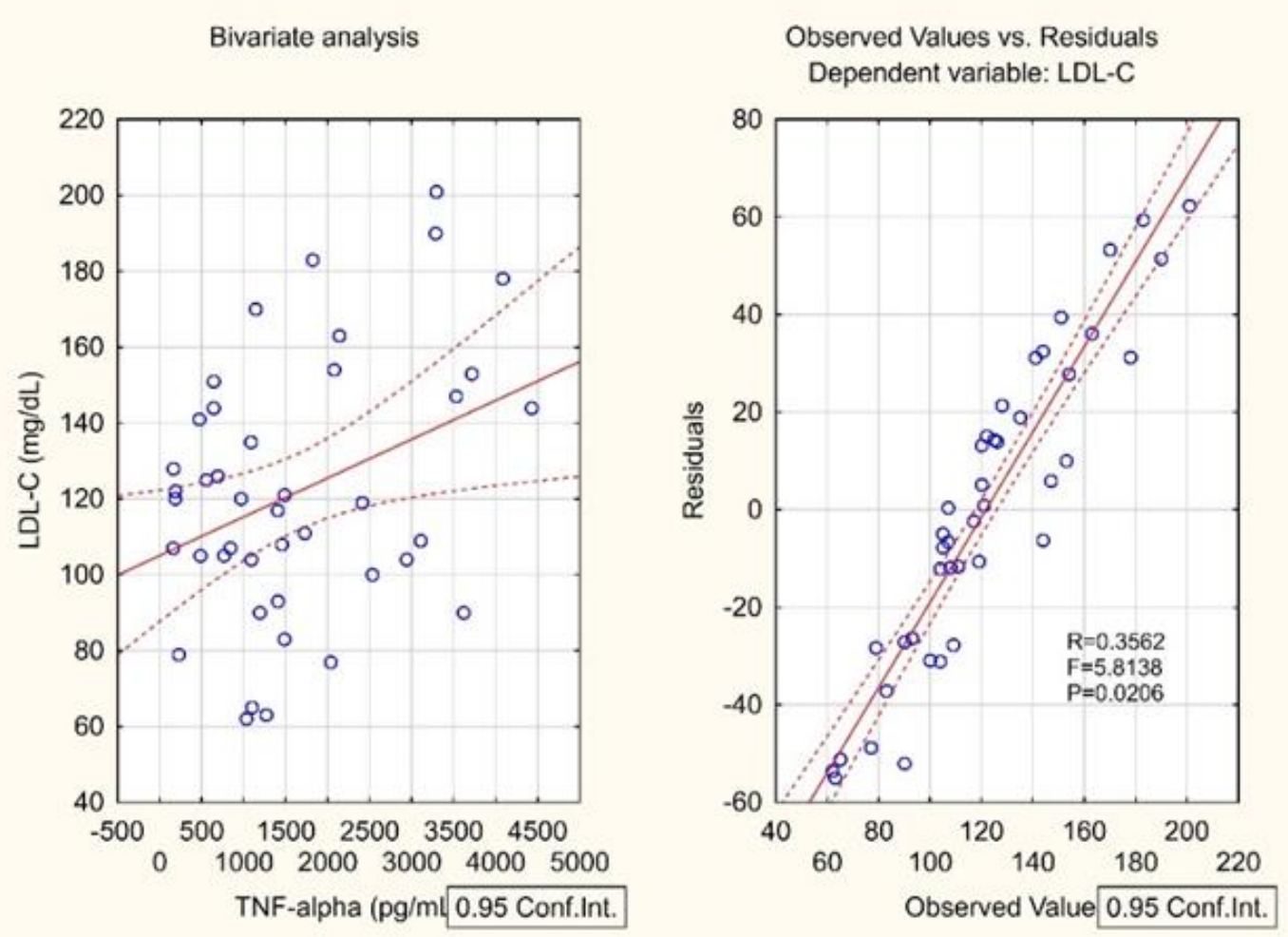

Figure 4 Correlation of TNF- $\alpha$ and LDL-cholesterol

Multiple regression analysis of post-exercise TNF- $\alpha$ (independent variable) and LDL-cholesterol (dependent variable). On bivariate and residual analysis, the correlation between these two variables is statistically significant $(\mathrm{R}=0.3562$, $\mathrm{F}=5.8138, \mathrm{P}=0.0206$,).

\section{Discussion}

We have demonstrated that long-term moderate intensity exercise reduces plasma levels of TC, LDL-C, and TC-HDL-C ratios and increases levels of HDL-C in the absence of statistically significant weight loss. We have correlated these changes with postexercise reductions in ex vivo PBMC production of the proinflammatory-proatherogenic cytokine, TNF- $\alpha$.

Other studies have shown that physical activity and exercise training have the potential to reduce blood levels of TC, LDL-C, and TC/HDL-C ratios, and increase blood levels of HDL-C $[6,7,15]$. These changes are reported as optimal when accompanied by weight loss, with, in one study, each kilogram of weight loss resulting in approximately $0.8 \mathrm{mg} / \mathrm{dL}$ reduction in LDL-C [6]. However, both weight loss without exercise training and, as was true in the current study, exercise training without weight loss can lower blood lipid levels $[6,17,18]$. In addition, there is evidence that the amount of exercise rather than the intensity of exercise may be more important in producing favorable changes in plasma lipid levels [17].

Others have reported that TNF- $\alpha$ may act as a regulator of lipid metabolism. Ito and associates found that serum levels of TNF- $\alpha$ correlated with LDL-C levels in adults [19] and Moon and associates found that serum levels of TNF- $\alpha$ and soluble TNF- $\alpha$ receptors were positively correlated with triglyceride levels and negatively correlated with HDL-C levels [20]. In addition, Fernández-Real and associates found that plasma levels of the soluble fractions of TNF- $\alpha$ receptors 1 and 2 were independent determinants of plasma TC and LDL-C in healthy adults [21].

The findings in our study are in keeping these reports and with what is known about the role of TNF- $\alpha$ in lipid metabolism. TNF- $\alpha$ has been shown to increase blood levels of TC and LDL-C by upregulating hepatic $\beta$-hydroxy- $\beta$ methylglutaryl-CoA [HMG-CoA] reductase mRNA expression [22] and to decrease blood levels of HDL-C by downregulating hepatic cell expression of scavenger receptor class B, type 1 (SR-B1) [23,24]. Hepatic HMG-CoA regulates the rate of cholesterol production and SR-B1 regulates the rate of cholesterol recycling by the liver by binding 
HDL-delivered cholesterol for processing and ultimate excretion in the stool (reverse cholesterol transport) [25-27]. TNF- $\alpha$ also inhibits hepatocyte synthesis of apolipoproteins A-1 and E, the principle transport proteins of HDL-C in the circulation and brain, respectively.

TNF- $\alpha$ also inhibits lipogenesis and stimulates lipolysis in adipose tissue by downregulating the production of adiponectin, an adipokine that enhances insulin sensitivity and improves the serum lipid profile through 5 'adenosine monophosphate-activated protein kinase [AMPK] activation and increased fatty acid oxidation [28]. The vast majority of TNF- $\alpha$ production in adipose tissue is from classically activated M1-polarized macrophages that are particularly abundant in white adipose tissue of overweight subjects and contribute to the pro-inflammatory nature of obesity [29].

Finally, TNF- $\alpha$ enhances foam cell uptake of oxidized LDL and inhibits cholesterol egress from foam cells extant in atherosclerotic plaques [30]. Thus, this potent proinflammatory cytokine plays a significant role in atherogenesis by promoting foam cell development and by upregulating hepatocyte production of cholesterol and downregulating reverse cholesterol transport.

\section{Conclusion}

We conclude that exercise-related reductions in blood lipids may occur as the result of corresponding reductions in immune cell production of tumor necrosis factor- $\alpha$, a proinflammatory/proatherogenic cytokine with known potential to influence hepatic, adipocyte, and monocyte/macrophage regulation of lipid metabolism.

\section{Compliance with ethical standards}

\section{Acknowledgments}

This study was supported by the Chair of Excellence in Medicine, Tennessee grant 20233.

\section{Disclosure of conflict of interest}

The authors declare that the submitted work was not carried out in the presence of personal, professional or financial relationships that could be potentially construed as a conflict of interest.

\section{Statement of ethical approval}

This study was approved by the James H. Quillen College of Medicine's Institutional Review Board. All participants signed an informed consent in the presence of one of the investigators.

\section{Statement of informed consent}

All study participants signed an informed consent in the presence of one of the investigators.

\section{References}

[1] Global Health Estimates. (2015). Deaths by Cause, Age, Sex, by Country and by Region, 2000-2015. Geneva: World Health Organization.

[2] Benziger CP, Roth GA and Moran AE. (2016). The global burden of disease study and the preventable burden of NCD. Global Heart, 11, 393-397.

[3] Chen I, Magliano DJ and Zimmet PZ. (2017). The worldwide epidemiology of type 2 diabetes mellitus - present and future perspectives. National Review of Endocrinology, 8, 228-236.

[4] Saklayen MG. (2018). The global epidemic of the metabolic syndrome. Current Hypertension Reports, 20 (2), 12.

[5] Sherling DH, Perumareddi P and Hennekens CH. (2017). Metabolic syndrome: clinical and policy implications of the new silent killer. Journal of Cardiovascular Pharmacology and Therapeutics, 22(4), 365-367.

[6] Kelley GA, Kelley KS and Tran ZV. (2005). Walking and Non-HDL-C in adults: a meta-analysis of randomized controlled trials. Previews in Cardiology, 8(2), 102-107.

[7] Gordon B, Chen S and Durstine JL. (2014). The effects of exercise training on the traditional lipid profile and beyond. Current Sports Medicine Reports, 13(4), 253-259. 
[8] Fletcher GF, Landolfo C, Niebauer J, Ozemek C, Arena R and Lavie, CJ. (2018). Promoting physical activity and exercise. Journal of the American College of Cardiology, 72, 1621-1639.

[9] Berg A, Halle M, Franz I and Keul J. (1997). Physical activity and lipoprotein metabolism: epidemiological evidence and clinical trials. European Journal of Medical Research, 2(6), 259-264.

[10] Lee JE, Sinnathurai P, Buchbinder R, Hill C, Lassere M and March L. (2018). Biologics and cardiovascular events in inflammatory arthritis: a prospective national cohort study. Arthritis Research and Therapy, 20, 171.

[11] Mathieu S, Dubost J-J, Tournadre A, Malochet-Guinamand S, Ristori J-M and Soubrier M. (2010). Effects of 14 weeks of TNF alpha blockade treatment on lipid profile in ankylosing spondylitis. Journal of Bone and Spine, 77, 50-52.

[12] Pollono EN, Lopez-Olivo MA, Lopez JA and Suarez-Almazor ME. (2010). A systemic review of the effect of TNFalpha antagonists on lipid profiles in patients with rheumatoid arthritis. Clinical Rheumatology, 29(9), 947-955.

[13] Van Sijl AM, Peters MJL, Knol DL, de Vet RHC, Sattar N, Dijkmans BAC et. al. (2011). The effect of TNF-alpha blocking therapy on lipid levels in rheumatoid arthritis: a meta-analysis. Seminars in Arthritis and Rheumatology, 41, 393-400.

[14] Kleinveld HA, Hak-Lemmers HLM, Stalenhoef AFH and Demacker PNM. (1992). Improved measurement of lowdensity-lipoprotein susceptibility to copper-induced oxidation: application of a short procedure for isolating lowdensity lipoprotein. Clinical Chemistry, 38 (10), 2066-2072.

[15] Nystoriak MA and Bhatnager A. (2018). Cardiovascular effects and benefits of exercise. Frontiers in Cardiovascular Medicine, 5, 135.

[16] Huttunen JK. (1982). Physical activity and plasma lipids and lipoproteins. Annals of Clinical Research, Supplement 34, 124-129.

[17] Kraus WE, Houmard JA, Duscha BD, Knetzger KJ, Wharton MB, McCartney JS, et. al. (2002). Effects of the amount and intensity of exercise on plasma lipoproteins. New England Journal of Medicine, 347, 1483-1489.

[18] Wood PD, Stefanick ML, Dreon DM, Frey-Hewitt B, Garay SC, Williams, PT, et. al. (1988). Changes in plasma lipids and lipoproteins in overweight men during weight loss through dieting as compared with exercise. New England Journal of Medicine, 319(18), 1173-1179.

[19] Ito H, Ohshima A, Tsuzuki M, Ohto N, Takao K, Hijii C, et. al. (2001). Association of serum tumor necrosis factor with serum low-density lipoprotein-cholesterol and blood pressure in apparently healthy Japanese women. Clinical Experimental Pharmacology and Physiology, 28(3), 188-192.

[20] Moon Y-S, Kim D-H and Song D-K. (2004). Serum tumor necrosis factor- $\alpha$ levels and components of the metabolic syndrome in obese adolescents. Metabolism, 53(7), 863-867.

[21] Fernăndez-Real JM, Gutiérrez C, Ricart W, Castiñeira M-J, Vendrell J and Richart C. (1999). Plasma levels of the soluble fraction of tumor necrosis factor receptors 1 and 2 are independent determinants of plasma cholesterol and LDL-cholesterol concentrations in healthy subjects. Atherosclerosis, 146, 321-327.

[22] Hardardóttir I, Moser AH, Memon R, Grünfeld C and Feingold KR. (1994). Effects of TNF, IL-1, and the combination of both cytokines on cholesterol metabolism in Syrian hamsters. Lymphokine and Cytokine Research, 13(3), 161166.

[23] Khovidhunkit W, Moser AH, Shigenaga JK, Grunfeld C and Feingold KR. (2001). Regulation of scavenger receptor class B type 1 in hamster liver and Hep3B cells by endotoxin and cytokines. Journal of Lipid Research, 42(10), 1636-1644.

[24] Song H, Saito K, Fujigaki S, Noma A, Ishiguro H, Nagatsu T, et. el. (1998). IL-1 $\beta$ and TNF- $\alpha$ suppress apolipoprotein (APO) E secretion and APO A-1 expression in HepG2 cells. Cytokine, 10(4), 275-280.

[25] Ohashi R, Mu H, Wang X, Yao Q and Chen C. (2005). Reverse cholesterol transport and cholesterol efflux in atherosclerosis. Quarterly Journal of Medicine, 98(12), 845-856.

[26] Wang HH, Garruti G, Liu M, Portincasa P and Wang DQ. (2017). Cholesterol and lipoprotein metabolism and atherosclerosis: recent advances in reverse cholesterol transport. Annals of Hepatology, 16 (Supplement 1: s3105): s27-s42.

[27] Lund-Katz S and Phillips MC. (2010). High density lipoprotein structure-function and role in reverse cholesterol transport. Subcellular Biochemistry, 51, 183-227. 
[28] Cawthorn WP and Sethi JK. (2008). TNF- $\alpha$ and adipocyte biology. F.E.B.S Letter, 582(1), 117-131.

[29] Roden M and Shulman GI. (2019). The integrative biology of type 2 diabetes. Nature, 576, 51-60.

[30] McLaren JE, Michael DR, Ashlin TG and Ramji DP. (2011). Cytokines, macrophage lipid metabolism and foam cells: implications for cardiovascular disease therapy. Progress in Lipid Research, 50, 331-347.

\section{How to cite this article}

Smith J, Dykes R and Chi DS. (2020). Exercise reduces plasma lipid levels by downregulating tumor necrosis factor- $\alpha$ production by peripheral blood mononuclear cells. World Journal of Advanced Research and Reviews, 6(3), 180-188. 